\title{
9 Gender Equity in STEM Higher Education in Kazakhstan
}

\author{
Anna CohenMiller, Aray Saniyazova, Anara Sandygulova \\ and Zhanna Izekenova
}

In much of the world, the landscape of higher education is built upon a male-model that has not systematically included the presence of women. For fields traditionally associated with men, there is a greater gap between women's enrollment, progression, and success compared to men. Such disciplinary fields that heavily engage men include science, technology, engineering, and mathSTEM. Women in comparison have historically been underrepresented in such fields. The discrepancy between women and men's presence in STEM can be attributed to multiple factors, such as restricted educational access (e.g. Chachashvili-Bolotin et al., 2016; McClure et al., 2017), pervasive stereotypes and bias (e.g., Cvencek et al., 2015), as well as a lack of mentors (e.g. Cacace, 2009; Dawson et al., 2015) and role models (Almukhambetova \& Kuzhabekova, 2020; Cacace, 2009; Holmes et al., 2018). Broadly speaking, women's underrepresentation in STEM fields in higher education is evident in extensive reviews of research on the topic (Blickenstaff, 2005) and in current statistics. For example, the UNESCO world report from 2014 to 2016 notes the "huge disparities" (Bokova, 2017, p. 5) in women's access and progression in STEM fields globally.

Within higher education, men's presence in STEM fields outweighs the presence of women in similar positions (Funk \& Parker, 2018; Hughes et al., 2017; Van Miegroet et al., 2019). While women are increasingly enrolling in STEM fields for their courses of study, they are not consistently employed within such fields. In the United States, women enroll in college STEM fields at a similar rate as men (Hughes et al., 2017), however, their path within the discipline varies greatly. When women enter the academic workplace, the progression from junior to senior scholar is fraught. In other words, the academic pipeline from doctoral student to full professor (CohenMiller, 2014) does not function the same for women and men. Instead, the academic pipeline is said to "leak" for women academics (Goulden et al., 2011, p. 147; Van Anders, 2004; Ysseldyk et al., 2019). The result in the leaky academic pipeline can be seen in the major discrepancy between women and men in leadership positions.

Such issues of progression, promotion, and retention for women in academia are well known and evidenced in Western contexts. However, the topic has been under-examined in other regions of the world. Therefore, this chapter draws

DOI: $10.4324 / 9781003053217-15$ 
attention to one such context needing further exploration, Central Asia. Specifically, we explore gender equity in STEM in higher education within Post-Soviet Kazakhstan. The following sections speak to the unique landscape of education in Kazakhstan, focusing on women's engagement and access to STEM higher education and employment. As such, we discuss how success can be interpreted as related to gender equity in STEM, provide an overview of the historical-cultural context of Kazakhstan which informs current educational practice and policy, and examine data about the topic. Using this information, we discuss ways in which women studying STEM fields in Kazakhstan can be compared to those in other contexts. Additional next steps are provided for bridging gaps in the academic pipeline for women in STEM in Kazakhstan and the Central Asian region.

\section{Gender Equity (or Lack Thereof) in STEM: A Review of International and Kazakhstani Research}

When we think about gender equity in STEM fields, it is important to consider how the topic is being addressed. The concept of "success" within STEM can be viewed in various ways. For instance, some U.S. and Canadian researchers study gender differences in STEM through the lens of access to graduate programs (Fried \& MacCleave, 2009; Weber, 2011), through the rate of graduation (Primé et al., 2015; Litzler et al., 2005), through attrition in jobs (Buffington et al., 2016), or through promotion (Bystydzienski, 2020). These aspects can also be considered as a whole, or as a part of the academic pipeline at the points where women are recruited, hired, retained, and promoted within higher education. The academic pipeline can provide an indicator of success. In this chapter, we look specifically at the concept of employability. The concept of employability relates in particular to the idea of getting a job in accordance with your degree. The factors affecting employability and relationship to one's degree tends to relate to international and external factors, including the sociocultural context.

Society plays a role in the way women consider their ability and position in STEM fields. For instance, Wei-Cheng et al., (2020) conducted a cross-cultural comparison of Taiwanese and U.S. high school students' STEM career aspirations and examined how parental involvement, learning experience, and selfefficacy relate to STEM career aspirations (Wei-Cheng et al., 2020). Wei-Cheng et al. (2020) found gender disparities exist across both types of countries - one that is collectivist in nature and one that is individualistic. Consistent with previous research on the topic of STEM aspirations, they showed that high school students evidence clear gendered differences in this regard, demonstrating that "gender inequity is a function of social-cognitive factors and self-efficacy is one of the most important factors predicting STEM career aspiration of high school students regardless of nationality" (Wei-Cheng et al., 2020, p. 40).

As noted by the UNESCO world report (2017) on girls' and women's education in science, technology, engineering, and mathematics, the gender 
discrepancy is deep-seated and needs to be examined through multiple lenses, including within schools: "Education systems and schools play a central role in determining girls' interest in STEM subjects and in providing equal opportunities to access and benefit from quality STEM education" (p. 11). Girls continue to receive messages that STEM fields are not intended for them (Koch et al., 2014). In Kazakhstan, such an examination of the gendered nature of education is being addressed in research about and within secondary schools (CohenMiller et al., 2020; Durrani et al., forthcoming). For example, it has been found that textbooks in Russian, Kazakh, and English for 7th and 8th graders reinforce traditional stereotypes of what it means to be a "good" boy/ man and a good girl/woman (Durrani et al., 2019, forthcoming). Imagery and descriptions which emphasize and reproduce gendered standards of beauty for women and intelligence for men can contribute to girls' interest and access to science in higher education and beyond.

Moreover, gender discrepancies and bias are also found in higher education. Wang and Degol (2017) point to evidence of such unconscious bias (see Knobloch-Westerwick et al., 2013; Moss-Racusin et al., 2012). Notions of who is considered to be a better student and employee can be seen as gendered, prioritizing men and devaluing women. As noted by Moss-Racusin et al. (2012), in the U.S. "both male and female faculty judged a female student to be less competent and less worthy of being hired than an identical male student, and also offered her a smaller starting salary and less career mentoring" (p. 9). They continued on to point out that bias was consistent across women and men faculty members even when controlling for other variables, suggesting the bias is "likely unintentional, generated from widespread cultural stereotypes" (Moss-Racusin et al., 2012, p. 9). Therefore, for women university students, they are consistently undervalued by students and faculty.

In Kazakhstan, CohenMiller and Lewis (2019) examined gender-related practices in higher education, focusing on the formal curriculum. Conducting a gender audit of authorship of assigned readings, they found that faculty favored readings by men, with only about $15 \%$ of all readings authored by women (CohenMiller \& Lewis, 2019). Such disproportionate gendered representation of scholarship would suggest to students that knowledge is primarily associated with men (CohenMiller \& Lewis, 2019). Not only does the formal curriculum in higher education emphasize the presence and knowledge of men, but so too do major scientific events. For instance, the Astana Expo in 2017 highlighted scientific advantages with pavilions curated by European and Asian countries. In a study conducted by CohenMiller et al. (2020), they found that across all countries, not one pavilion had an equal representation of men and women in the imagery of science. In other words, both formal learning in institutions of higher education, as well as informal learning through media representations, propagate and reproduce gendered roles, largely ignoring women in STEM.

Other research in Kazakhstani higher education explored students' experiences in the transition to postsecondary education in Kazakhstan and 
determinants associated with their decisiveness to enroll in STEM majors (Almukhambetova \& Kuzhabekova, 2020). Almukhambetova and Kuzhabekovam (2020) identified the existence of contradictory societal expectations about gender roles and norms in schools and workplaces and the lack of women role models in STEM in Kazakhstan. Moreover, focusing on the academic pipeline, Kuzhabekova and Almukhambetova (2019) studied women's progression through leadership positions in two adjacent countries in Central AsiaKazakhstan and Kyrgyzstan. They found that informal networking can create barriers to the advancement of women and decrease promotion opportunities for those women who are outside of this "informal patronage network" (p. 14).

Across these studies, what continues to be evident is the need to further understand issues of equity and access for women in STEM fields in Kazakhstan, especially considering the gendered discrepancies which continue to persist despite country-wide efforts. Nationwide steps and programs have included those by international organizations and local initiatives (e.g. Ministry of Education and Science, Colorado STEM Summer Camp for girls from Kazakhstan, TechGirls, Girls in STEM) (for example, see U.S. Mission to International Organizations in Vienna, 2018). Some such efforts in Kazakhstan have included the State Program for the Development of Education and Science, which emphasized the importance of science education for both boys and girls. According to the State Program for the Development of Education and Science of the Republic of Kazakhstan, for 2016-2019, the new content education contains the elements of STEM education aimed to develop new technologies, scientific innovations, and mathematical modeling (On approval of the State Program for the Development of Education and Science of the Republic of Kazakhstan for 2016-2019, 2018). Moreover, other initiatives include programs organized by the U.S. Embassy and Consulate in Kazakhstan (2020), as well as, TechGirls four-week exchange program, the weeklong Destination Mars! Camp, and the Chevron sponsored Girls in STEM twoweek summer program based in Almaty, Kazakhstan (Seidakhmetova, 2019).

Other initiatives have included a recent program launched by UNICEF to encourage girls in STEM. The program focuses specifically on teaching and modeling the development of nanosatellites for girls and women between the ages of 14 and 35 (UNICEF, 2020). The UNDP in 2019 also highlighted women's and girls' contributions to technology by celebrating International Girls in ICT Day with the development and implementation of a program to distribute automated messages about gender equality - a gender bot (Kazin form International News Agency, 2019).

In summary, the continuing issues faced by women in STEM in Kazakhstan reflect the fact that men outnumber women in multiple STEM careers (UNESCO, 2016). As a result, men are more likely to be promoted to managerial positions. Moreover, in the Kazakhstani context there appears to be additional social-cultural factors that contribute to the underrepresentation of women in STEM. These factors, which will be discussed in further detail below, include the historical and cultural context of the country (Hofstede, 1991). 


\section{Historical and Cultural Context of Kazakhstan: A Unique Landscape}

Historically, the main role of women in Kazakh society was that of wife and mother. There is an old saying, "Daughter is a guest in the family," which implies that girls are expected to be treated with love and care in their families as once they get married they will accept the burden of household chores in their husband's house, including taking care of in-laws. In a nomadic society, such work implied not only working inside the home but also helping men with the herds and other outdoor activities. However, despite that, hardworking women were considered to be of a lower social status. When Kazakhstan was part of the Soviet Union, the issue of so-called "women's emancipation" was given great attention. Regulations and policies accepted at that time strove to provide women with equal access to education, healthcare, and labor force participation. Women were provided various social benefits to foster their education at all levels and encourage their active involvement in the socio-economic and political life of society (McLaughlin, 2018). Soviet-era efforts have created a foundation for gender equality and have been continued by independent Kazakhstan. After independence, Kazakhstan introduced national policies in accordance with international regulations aimed at advancing gender equality across various spheres such as the Beijing Platform of Action (endorsed in 1995), the Convention on the Elimination of All Forms of Discrimination against Women (CEDAW) (ratified in 1998), and the CEDAW Optional Protocol (ratified in 2001) (McLaughlin, 2018).

According to the Kazakhstan Country Gender Assessment (CGA) carried out by the Asian Development Bank in 2018, Kazakhstan is placed in Group 1 that comprises the countries where key gender and development indicators demonstrate high equality between men and women (McLaughlin, 2018). However, despite the overall reduction on the Gender Inequality Index, and relatively high equality in key indicators of the assessment, which are health, education and command over economic resources, Kazakhstan still ranks low in indicators for political representation of women (only 20.1\% parliamentary seats held by women), women's labor force participation $(66.1 \%$ compared to $77 \%$ for men), and gender wage differences (Agency of the Republic of Kazakhstan on Statistics, 2020). In terms of gender-based discrimination in social norms, practices, and laws, Kazakhstan shows low-level discrimination in the following dimensions: (i) discriminatory family code, (ii) restricted physical integrity, (iii) son bias, (iv) restricted resources and assets, and (v) restricted civil liberties, as measured by the Social Institutions and Gender Index (SIGI).

Though these facts demonstrate that women's social status has significantly changed and the concept of equality between men and women is widely accepted in modern Kazakh society, the traditional stereotype of women's role as wife, mother and daughter-in-law remains primary in public discourse (Akiner, 1997). For example, according to the Labor Code of Kazakhstan, both parents are entitled to three years of parental leave of which one year is 
paid with a monthly allowance up to $40 \%$ of their average salary. However, as men are culturally associated with the workplace, it is not surprising to see statistics indicating that predominantly women use parental leave (McLaughlin, 2018). Despite the fact that the Constitution, Labor Code, and other legal documents provide women and men with equal rights, the traditional cultural norms still have decisive power in many aspects of life in Kazakhstan. Women in Kazakhstan, by and large, are expected to both maintain a professional occupation and perform housework and childcare.

As Wei-Cheng et al. (2020) note, sociocultural context plays an important role in understanding gender disparities in STEM fields. In collectivist societies, such as Japan, the pressure for women to fulfill their social responsibilities can limit professional opportunities (Yoshikawa et al., 2018). Such findings are echoed in research about gendered roles and perceptions of students living in collectivist nations pursuing STEM careers (Wei-Cheng, et al., 2020). And in Kazakhstan, expectations and associations for women to take on the responsibilities of raising children, cleaning, cooking, as well as a career have repercussions on gender equity throughout the educational pipeline. To better understand gender equity in STEM fields in Kazakhstan, the following case study from a unique university within the country is presented. The study provides a deeper examination into admissions and progression for undergraduate and graduate students, as well as speaking to gender equity as shown in hiring and promotion for faculty.

\section{Case Study: An Examination into the School of Engineering and Digital Sciences-Undergraduate Students, Graduate Students, and Faculty}

The admission of university students in Kazakhstan is influenced by financial aspects of the higher education system. Universities in Kazakhstan have tuition fees and there are a limited amount of state grants awarded to those students with high performance in the nationwide, high-stakes exam - the Unified National Testing (UNT). The available grants for studying in higher education vary based upon the discipline. Grants to study in STEM fields far outweigh grants in social sciences and humanities fields, the latter being almost non-existent. A result of grants emphasizing STEM fields is that high school graduates often select those disciplines to avoid paying tuition fees. Therefore, students may prioritize finances over their interest in STEM. If a student reaches a certain number of points on the UNT, they can be offered a grant. For example, in Kazakhstan in 2020, the largest proportion of grants went to those interested in studying for an MS in Mechanical Engineering. If a student reaches 91 points on the UNT, they could receive that grant. However, for a student to be awarded a grant in Management or Law, they would need a 97 and 104, respectively (National Testing Center, 2020).

Nazarbayev University (NU) is unique within Kazakhstan because it does not require UNT scores; instead, it has a three-stage admission process. After submission of an application, the first stage is the British Council-developed 
Aptis exam, an assessment of English language skills. This assessment can be waived if an applicant has achieved a "competent" score (a 6.0 or higher) across all sections on the high-stakes International English Language Testing System (IELTS) exam. If an applicant scores a minimum passing score (165 out of 200), they proceed to the second stage. The student then takes an NU entrance test in English in two subjects-Mathematics and Critical Thinking and Problem Solving. Successful candidates move to the third stage. The third stage includes the IELTS examination where the minimum passing score is 6.0, indicating competence in English across all the sections. For graduate programs, the admission process is different. It consists of two stages: submission of the application with supporting documents including a language proficiency certificate, optional GRE certificate, and statement of purpose. Letters of recommendation are submitted directly to an admission committee, after which the candidate may proceed to an interview with the committee.

NU provides full funding to all accepted students regardless of major. This case study was conducted using data about both undergraduate and graduate students. It includes data from students enrolled in the BS, BEng, MS and $\mathrm{PhD}$ programs of the School of Engineering and Digital Sciences (SEDS). An autonomous research university in the capital of Kazakhstan, NU was founded in 2010 (Nazarbayev University, 2020). It is an English-medium institution with $75 \%$ of the faculty coming from international locations. Of the 441 faculty members, 34\% are women (NU). Apart from SEDS, NU has a School of Sciences and Humanities, Graduate School of Education, School of Mining and Geosciences, School of Medicine, and others. With a high aim of becoming the national brand of Kazakhstan higher education, NU is considered a highly prestigious and competitive university for Kazakhstani youth as it provides tuition-free education to its students similar to the fully funded King Abdullah University of Science and Technology (2020) in Saudi Arabia.

Because NU does not require UNT scores and provides full funding for those admitted, we believe there is a more realistic picture of students' selected major being driven by interest rather than financial need. Therefore, we see that this case study conducted on the data from NU students represents trends regarding women's interest in STEM fields and their potential accessibility.

Figure 9.1 demonstrates the percentage of women students accepted to the BS and the BEng degrees in six programs within the SEDS school for the last six years (2015-2020). The six programs include: BEng in Chemical Engineering, BEng in Civil Engineering, BS in Computer Science, BEng in Electrical and Electronic Engineering, BEng in Mechanical Engineering, BS in Robotics and Mechatronics. The most popular program for women is the BEng in Chemical Engineering as seen from the percentages of enrolled women students, which is the highest among the SEDS programs (average is $51 \%$ ). Since its inception, the numbers have increased at a steady rate for this program starting from $43 \%$ in 2015 to $64 \%$ in 2020. BEng in Electrical and Electronic Engineering and BEng in Mechanical Engineering also had a steady increase in numbers ranging from $6 \%$ in 2016 to $26 \%$ in 2020 and 


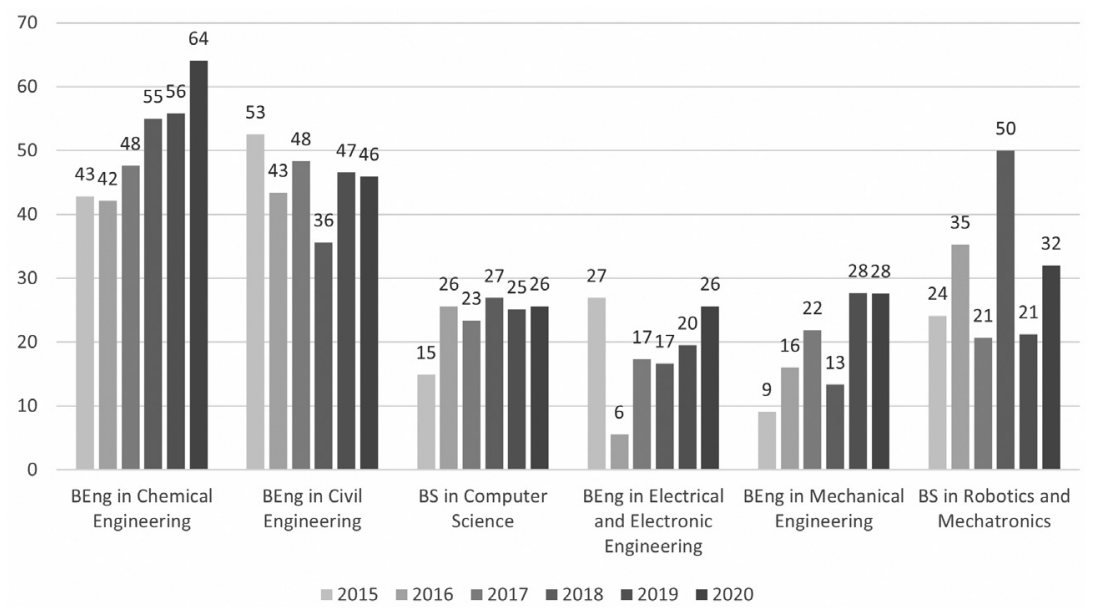

Figure 9.1 Percentage of women in BS and BEng degrees across six programs of SEDS for 2015-2020.

from $9 \%$ in 2016 to $28 \%$ in 2020, respectively. The growth seen in these programs for women students showed a slight decrease for the BS in Civil Engineering (from 53\% in 2015 to $46 \%$ in 2020). The BS in Computer Science and the BS in Robotics and Mechatronics continue to demonstrate stable numbers over the six year period with an average of $24 \%$ and $31 \%$ of women students in each program, respectively. Interestingly, the proportion of women in BS in Robotics and Mechatronics was unusually high at 50\% in 2018 with a sharp increase from $21 \%$ in 2017 followed by a sharp decrease back to $21 \%$ in 2019 .

In Figure 9.2 the graph plots the percentage of women students accepted to MS degrees in six programs within the SEDS school for the last six years (2015-2020). The six programs include: MS in Engineering Management, MS in Electrical and Computer Engineering, MS in Mechanical and Aerospace Engineering, MS in Robotics, MS in Civil and Environmental Engineering, and MS in Chemical and Materials Engineering. Overall, the percentage of women students increased at a steady rate for the MS in Mechanical and Aerospace Engineering from $13 \%$ in 2015 to $36 \%$ in 2020, while the percentage of women for the MS in Electrical and Computer Engineering and the MS in Civil and Environmental Engineering slightly decreased in the last two years from $46 \%$ in 2018 to $30 \%$ in 2020 and from $67 \%$ in 2018 to $30 \%$ in 2020, respectively. The MS in Engineering Management and the MS in Chemical and Materials Engineering programs continue to demonstrate steady numbers over the six year period with an average of $48 \%$ and $53 \%$, respectively, whereas the number of women in the MS in Robotics fell to zero for two years in 2018-2019 and increased sharply to $38 \%$ in 2020 . 


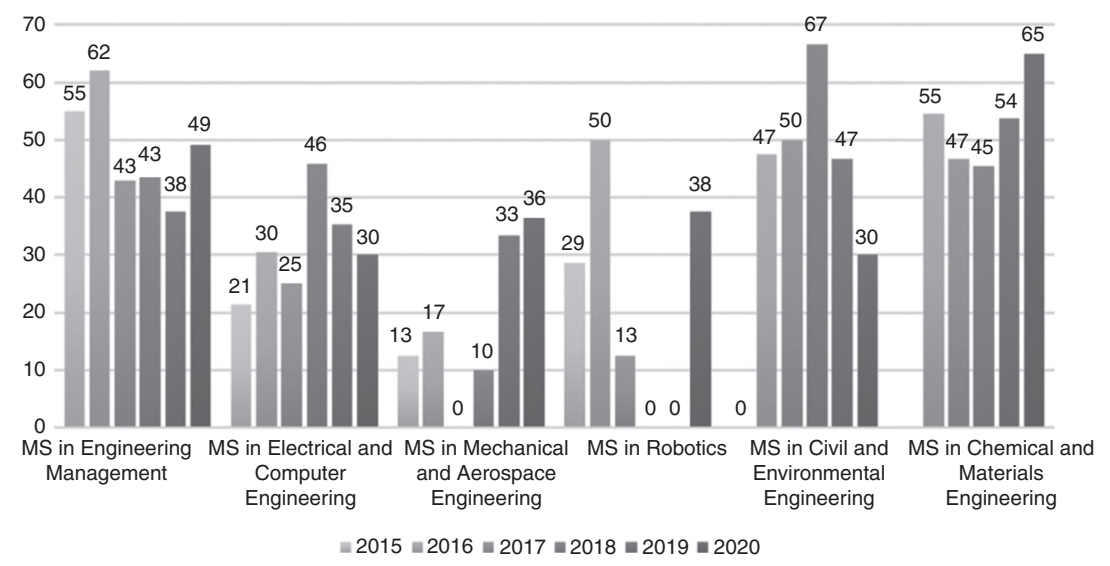

Figure 9.2 Percentage of women in MS degrees across six programs of SEDS for 2015-2020.

The enrollment trends for the MS in Engineering Management and the MS in Chemical Materials and Engineering programs indicate they are the two most popular programs among women with averages of $48 \%$ and $53 \%$ of enrollments over the last six years in each program, respectively. This trend was also demonstrated for the undergraduate program of the BEng in Chemical Engineering with an average of $51 \%$ women. While both the BEng in Civil Engineering and the MS in Civil and Environmental Engineering programs have a slight decline in numbers, they have almost the same average of women and men with an average of $45.5 \%$ and $40 \%$ for women, respectively. The department of Robotics and Mechatronics was the next least popular choice for women, where the numbers from the undergraduate program in the BS in Robotics and Mechatronics are slightly higher than for the MS in Robotics, which have $31 \%$ and $21 \%$, respectively. The next pair has even lower numbers with women in the BEng in Electrical and Electronic Engineering and the MS in Electrical and Computer Engineering averaging only 19\% and 31\%, respectively. In general, the next pair of the BEng in Mechanical Engineering and the MS in Mechanical and Aerospace Engineering demonstrates a similar trend and has the lowest numbers of women with an average of $19 \%$ and $18 \%$, respectively.

Since the overall numbers are limited in all programs across SEDS, broad conclusions may not be representative. From this data, it is possible to see a level of parity between genders for some programs, or the lack thereof for others. In the BS/BEng and MS SEDS programs at NU, two-thirds of the programs show near gender parity.

Regarding the SEDS PhD programs, the percentage of women across the whole school is $46 \%$ and showed a decreasing trend (from 54\% in 2015 to $40 \%$ in 2018) followed by a slight increase to $43 \%$ in 2020 . Interestingly, three $\mathrm{PhD}$ programs in Computer Science, Chemical Engineering, and Civil Engineering 
have exactly $50 \%$ women enrollment in 2020 . Similar to its MS counterpart, the $\mathrm{PhD}$ in Electrical Engineering includes $40 \%$ women, while two $\mathrm{PhD}$ programs, the $\mathrm{PhD}$ in Robotics and the $\mathrm{PhD}$ in Mechanical Engineering, demonstrated the lowest ratio of $20 \%$.

In 2020, among the graduates of MS programs, four programs showed a greater representation of women to men with $71 \%$ in the MS in Chemical and Material Engineering, $67 \%$ in the MS in Civil and Environmental Engineering, 57\% in the MS in Chemical Engineering, and 53\% in the MS in Electrical and Computer Engineering. There were seven programs where men outnumbered women, although with near gender parity in the MS in Engineering Management with women representing $42 \%$ of the total graduates. In Civil Engineering and Computer Science, MS graduate women included $39 \%$ and $36 \%$, respectively. Then the numbers of women graduates decrease dramatically to only $15 \%$ for the MS in Electrical and Electronic Engineering, 14\% for the MS in Robotics, 9\% for the MS in Mechanical Engineering, and no women in Mechanical and Aerospace Engineering.

Across the $\mathrm{PhD}$ programs, there is greater gender parity as compared to the undergraduate BS/BEng and MS programs. This finding might be explained by the fact that top men who graduate from the BS/BEng and MS programs often continue in a $\mathrm{PhD}$ program abroad while women are more likely to stay in a local $\mathrm{PhD}$ program. For women in Kazakhstan, choosing to continue in academia is more acceptable than employment in engineering, which is often located in geographically remote areas, with a need for long-term shifts away from the family.

These data from the undergraduate and graduate programs in the School of Engineering and Digital Sciences from 2015 to 2020 indicate that the majority of programs enroll and support men more than women. Yet, there are a few programs demonstrating gender parity or even greater enrollment of women in select STEM fields. The growing number of women in STEM fields at the university can be considered a sign in the right direction for gender inclusion in higher education. However, to ensure the move from gender parity (counting the number of individuals) to gender equity (fair and just treatment of women and men), it is important to consider the academic pipeline and women's progression through it. For example, when identifying the number of faculty members, there is a significant imbalance between women and men, with the vast majority of women in positions on the lowest rung of the academic ladder and men in all positions of leadership (Nazarbayev University School of Engineering and Digital Sciences, 2020).

Overall, the admission process at NU is both unique in its process and also its state funding. As shown internationally, students from cities with higher quality education have increased access to top universities. The same is true in Kazakhstan, as those in urban areas have greater access to high quality high school/secondary education, including private tutoring for high-stakes tests. 
For women students, especially those from cities other than the two major ones (Nur-Sultan and Almaty), and those from rural areas, the recruitment process is particularly important. Following Posselt's (2016) work on graduate admission and the issue of "who falls through the cracks," future research should examine issues of geographic equity for women and include rural women in recruitment, admissions, and progression initiatives in Kazakhstan.

\section{Lack of Women Mentors in STEM}

Considering the importance of mentorship in moving to future employment, an imbalance in women and men could strongly disadvantage either group of students. At NU, in the School of Engineering and Digital Sciences, there are 105 faculty members with 15 women representing approximately $14 \%$. Of the 15 women faculty, seven are in more temporary positions, working as postdoctoral scholars and instructors. These positions are often considered to be non-tenure track and require leaving the institution to find employment elsewhere after a limited amount of time. Of the remaining seven women in SEDS, which represents $6 \%$ of the faculty in the School, five are employed at the entry level as Assistant Professors and two have been promoted or recruited to Associate Professor. Apart from one position filled by a woman, Acting Vice-Dean of Academic Affairs, only men have been promoted or recruited as full professors or to positions of leadership such as Department Chair.

Overall, these descriptive data of SEDS undergraduate and graduate students as well as faculty at NU indicates common evidence that women's enrolment in university degrees in STEM may be on the rise in some departments but as a whole remain stunted compared to men. For STEM faculty recruited, hired, and promoted through the academic ranks there is evidence that problems exist in the academic pipeline. While there are increasing numbers of women enrolled in STEM fields, they are not systematically being inducted into academic positions. Instead, as shown internationally, women in academic positions are underrepresented, which can be attributed to sociocultural, historical, and institutional structures.

\section{Discussion and Takeaways}

Across countries, whether "developed" or "developing," or collectivist or individualistic nations, efforts continue to be implemented to address gender discrepancies of women in STEM. Yet, senior-level positions in higher education as well as in other workplaces continue to indicate a problem in the academic pipeline. Despite this troublesome trend, gender inequity in higher education is a topic of importance regularly researched internationally. Thus, while there continues to be evidence of structural and cultural obstacles, there is also hope for both gender parity and gender equity.

The potential challenges highlighted in this chapter speak to various sociocultural and historical contexts including the collectivist nature of Kazakhstan, 
the Post-Soviet context of women in the workforce, and traditional cultural practices. The combination of these cultural and political contexts infiltrate the educational system and are reproduced in educational and cultural media. These gendered representations teach consumers what it means to be a woman or a man and what professional fields are encouraged for each gender.

Interventions to address gender discrepancy and move towards gender equity need to start early and be incorporated throughout educational and cultural spheres. Such an approach is what Wang and Degol (2017) mention as "lifelong," including representation in the media to "strive to create more positive portrayals of female professionals in STEM fields, so that girls and women encounter wellrounded and realistic images of successful women scientists" (p. 131). Without recognizing the sociocultural influence, it can be easy to fall into the trap of telling women they need to "try harder," "negotiate more," or "lean in" (Sandberg \& Scovell, 2013). However, as Kim et al. (2018) note, the messages coming from the concept of leaning in (trying harder) can be problematic when major changes are needed structurally and socially; "self-improvement messages intended to empower women to take care of gender inequality may also yield potentially harmful societal beliefs" (p. 974). Thus, recognizing the multifaceted nature of pressures and culture is essential when addressing gender equity in STEM.

In addition to the sociocultural and historical context, role models and mentorship is recognized as essential for steady movement through the academic pipeline. In other words, having a lack of women across academic ranks in STEM fields can be an impediment to gender equity. As shown in the case study at NU, women represented less than $10 \%$ of all faculty in the School of Engineering and Digital Sciences, across six departments. Therefore, while there appears to be a growing trend of more women enrolling in STEM fields at this university in Kazakhstan, representation of STEM knowledge and leadership remains firmly held by men.

Mentorship can be considered from different perspectives, such as a means to show women the potential for support and connectedness (Wang \& Degol, 2017) and as a means to incorporate marginalized voices. Wang and Degol (2017) emphasize the importance of women mentors and peers throughout the academic pipeline because without women colleagues' support and connection, women may hesitate to pursue STEM careers. Ultimately, a central component to supporting women as undergraduate, master's and doctoral students in STEM is to increase gender equity among faculty.

Connected to mentorship and role models is the relevance of the work environment for women (Fouad et al., 2020), including addressing familial obligations for mothers and also for fathers (Wang \& Degol, 2017). As Fouad et al. (2020) explain, employers have an obligation to improve gender equity in the STEM workplace by implementing policies that provide opportunities for both men and women to advance, achieve goals, and balance their different roles. In Post-Soviet Kazakhstan, in combination with creating gender equitable departments of STEM faculty, the STEM work environment could be a particularly effective means to address the traditional and evolving roles expected of women. 


\section{Potential Challenges and Opportunities for Growth}

In Post-Soviet Kazakhstan, the challenges for gender equity in STEM in higher education is based upon three primary factors: traditional expectations of women's roles, continued emphasis on men as bearers of knowledge, and structural obstacles to and through the academic pipeline. Unfortunately, these challenges are not unique to Kazakhstan and can be seen throughout the world. Yet, internationally these challenges of gender equity are being discussed, and that is a first step. There is a growing awareness of issues of gender equity, the lack of role models, and problems in hiring and promotion.

While traditional roles and Soviet-history remain, there is also a burgeoning desire for change and an incredible speed at which changes are being made. Therefore, opportunities in Kazakhstan and other similar contexts may not need an excessive amount of time to create and implement changes. For instance, the government in Kazakhstan in 2009 introduced a law to guarantee equal rights and opportunities for men and women (2009), developed an action plan for gender policies through 2030 (Government of the Republic of Kazakhstan, 2017), and implemented the concept of family and gender policy (Ministry of Justice of the Republic of Kazakhstan, 2016).

Therefore, while Kazakhstan faces challenges regarding gender disparity in STEM disciplines and careers, there are steps that can be taken which could effectively move the nation towards gender equity. According to international and regional research, relevant practices for Kazakhstan and similar nations could include the following:

- Create spaces for mentoring girls and women in STEM disciplines, such as culturally responsive STEM training and camps (Ashford et al. 2017; Chukwurah \& Klein-Gardner, 2014; Taube \& Polnick, 2014).

- Take active steps to attract more women in STEM. One such way to effectively highlight the position of women in STEM is to alter the way sciences are taught in schools. For example, schools can include more imagery of women scientists, focus counseling on encouraging girls in STEM (Wei-Cheng, Shr-Jya, Jiaqi \& Johnson, 2020), and engage in more storytelling within science teaching to tap into talents typically associated with girls and women (Wang \& Degol, 2017).

- Develop and implement training and work toward institutional transformation surrounding issues of unconscious bias in higher education (CohenMiller \& Lewis, 2019), including addressing differences in recommendation letters for women and men (Bilimoria \& Liang, 2012).

- Alter the workplace culture to increase transparency and fairness in expectations for research (Willey, 2020) and eliminate the "motherhood penalty" (Mason et al., 2005) and the "chilly climate" for women in STEM (Hughes, 2014). Such changes could create a "culture of care" (Isgro \& Castañeda, 2015) and an organization which recognizes the 
relevance and need for equity and inclusion for women in academia, throughout all levels and disciplines.

\section{Conclusion}

In this chapter, we examined the topic of gender parity and equity in STEM fields in Kazakhstan. We investigated gender equality in the academic environment at the international level and research on gender and education in Kazakhstan. The country's sociocultural expectations creates pressure for women to have professional careers and simultaneously take on the responsibility of raising children, taking care of the home, and looking after older relatives. These expectations and associations for women who take on these multiple roles are reflected in the lack of gender parity and equity throughout the educational pipeline.

In this chapter, we used the case study of STEM undergraduate and graduate students and an examination of gender parity among faculty at Nazarbayev University to analyze the admission and progress of students and the gender gap among faculty in STEM disciplines. Through this examination, we argued the gendered imbalance of STEM university students and faculty should be addressed in multiple ways to promote gender parity and equity, including through raising awareness of gender bias disadvantaging women, through creating STEM spaces for women including focused mentoring to facilitate success, and through targeted recruitment, retention, and promotion practices.

\section{References}

Agency of the Republic of Kazakhstan on Statistics. (2020). https://stat.gov.kz/

Akiner, S. (1997). Between tradition and modernity: The dilemma facing contemporary Central Asian women. In M. Bruno, (Ed.), Post-Soviet women: From the Baltic to Central Asia (pp. 261-304). Cambridge University Press.

Almukhambetova, A., \& Kuzhabekova, A. (2020). Factors affecting the decision of female students to enrol in undergraduate science, technology, engineering and mathematics majors in Kazakhstan. International Fournal of Science Education, 1-21.

Ashford, S. N., Wilson, J. A., King, N. S., \& Nyachae, T. M. (2017). STEM 'sista' spaces: Creating STEM counterspaces for Black girls and women. In T. S. Ransaw \& R. Majors (Eds.), Emerging issues and trends in education (pp. 3-38). Michigan State University Press.

Bilimoria, D., \& Liang, X. (2012). State of knowledge about the workforce participation, equity, and inclusion of women in academic science and engineering. In D. Bilimoria \& X. Liang (Eds.), Gender equity in science and engineering (pp. 16-45). Routledge.

Blickenstaff, J. C. (2005). Women and science careers: Leaky pipeline or gender filter? Gender and Education, 17(4), 369-386. https://doi.org/10.1080/09540250500145072

Bokova, I. (2017). Foreword. In C. Chavatzia (Ed.), Cracking the code: Girls' and women's education in science, technology, engineering and mathematics (STEM) (p. 5). UNESCO.

Buffington, C., Cerf, B., Jones, C., \& Weinberg, B. A. (2016). STEM training and early career outcomes of female and male graduate students: Evidence from UMETRICS data linked to the 2010 census. American Economic Review, 106(5), 333-338. 


\section{Anna CohenMiller et al.}

Bystydzienski, J. M. (2020). Gender and STEM in Higher Education in the United States. In Oxford research encyclopedia of education. Oxford University Press.

Cacace, M. (2009). Guidelines for gender equality programmes in science. Practising Gender Equality in Science. www.retepariopportunita.it/Rete_Pari_Opportunita/UserFiles/ Progetti/prages/pragesguideline s.pdf

Chachashvili-Bolotin, S., Milner-Bolotin, M., \& Lissitsa, S. (2016). Examination of factors predicting secondary students' interest in tertiary STEM education. International Fournal of Science Education, 38(3), 366-390.

Chukwurah, C., \& Klein-Gardner, S. S. (2014). STEM summer institute: A model program for stem integration for girls. In J. Koch, B. Polnick, \& B. Irby. (Eds). Girls and women in STEM: A never ending story (pp. 153-174). Information Age Publishing.

CohenMiller, A. S. (2014). The phenomenon of doctoral student motherhood/mothering in academia: Cultural construction, presentation of self, and situated learning. [Unpublished doctoral dissertation]. University of Texas at San Antonio.

CohenMiller, A. S., \& Lewis, J. (2019). Gender audit as research method for organizational learning and change in higher education. In V. Demos, M. T. Segal, \& K. Kelly (Eds.), Gender and practice: Insights from the field: Vol. 27. Advances in gender research (pp. 39-55). Emerald Publishing. https://www.emerald.com/insight/content/doi/10.1108/S1529-212620190 000027003/full/html

CohenMiller, A. S., Koo, S., Collins, N., \& Lewis, J. (2020). EXPOsing gender in science: A visual analysis with lessons for gender awareness and science diplomacy. Gender, Technology and Development. https://doi.org/10.1080/09718524.2019.1695519

Gvencek, D., Kapur, M., \& Meltzoff, A. N. (2015). Math achievement, stereotypes, and math self-concepts among elementary-school students in Singapore. Learning and Instruction, 39, 1-10.

Dawson, A. E., Bernstein, B. L., \& Bekki, J. M. (2015). Providing the psychosocial benefits of mentoring to women in STEM: CareerWISE as an online solution. New Directions for Higher Education, 2015(171), 53-62.

Durrani, N. Kataeva, Z., CohenMiller, A., \& Makhmetova, Z. (in press). Teacher agency for gender justice in Kazakhstan [Conference presentation]. Comparative \& International Education Society (CIES).

Durrani, N., Kataeva, Z., CohenMiller, A., Seitkhadyrova, A., \& Badanova, A. (2019). The fearful khan and the delightful beauties. Masculinities and femininities in school textbooks in Kazakhstan [Conference presentation]. Central Eurasian Studies Society (CESS) Conference, Washington, DC.

Durrani, N., Kataeva, Z., CohenMiller, A., Seitkhadyrova, A., \& Badanova, A. (2020, March 25). "Ann's much __ (beautiful) than Mary": Gendered discourses in secondary school textbooks in Kazakhstan [Conference presentation]. CIES 2020 Education beyond the Human, Miami, Florida.

European Bank for Reconstruction and Development (EBRD). (2016). Life in transition: Kazakhstan. https://www.ebrd.com/what-we-do/economic-research-and-da ta/data/lits.html

Fouad, N. A., Kozlowski, M. B., Singh, R., Linneman, N. G., Schams, S. S., \& Weber, K. N. (2020). Exploring the odds: Gender differences in departing the engineering profession. Journal of Career Assessment, 28(3), 446-461. https://doi.org/10.1177/ 1069072719876892

Fried, T., \& MacCleave, A. (2009). Influence of role models and mentors on female graduate students' choice of science as a career. Alberta Fournal of Educational Research, $55(4)$. 
Funk, C., \& Parker, K. (2018). Women and men in STEM often at odds over workplace equity. Pew Research Center. https://www.pewsocialtrends.org/2018/01/09/women-a nd-men-in-stem-often-at-odds-over-workplace-equity/

Goulden, M., Mason, M. A., \& Frasch, K. (2011). Keeping women in the science pipeline. The ANNALS of the American Academy of Political and Social Science, 638(1), 141-162

Government of the Republic of Kazakhstan. (2017). Implementation action plan on the concept of family and gender policy in the Republic of Kazakhstan until 2030 (the first stage 2017-2019). https://online.zakon.kz/m/document/?doc_id=37659563

Hofstede, G. (1991). Empirical models of cultural differences. In N. Bleichrodt \& P. J. D. Drenth (Eds.), Contemporary issues in cross-cultural psychology (pp. 4-20). Swets \& Zeitlinger Publishers.

Holmes, K., Gore, J., Smith, M., \& Lloyd, A. (2018). An integrated analysis of school students' aspirations for STEM careers: Which student and school factors are most predictive? International Fournal of Science and Mathematics Education, 16(4), 655-675.

Hughes, C. C., Schilt, K., Gorman, B. K., \& Bratter, J. L. (2017). Framing the faculty gender gap: A view from STEM doctoral students. Gender, Work \& Organization, 24 (4), 398-416.

Hughes, R. (2014). The evolution of the chilly climate for women in science. In J. Koch, B. Polnick \& B. Irby (Eds), Girls and women in STEM: A never ending story (pp. 71-94). Information Age Publishing.

Isgro, K., \& Castañeda, M. (2015). Mothers in US academia: Insights from lived experiences. Women's Studies International Forum. 53, 174-181.

Kazinform International News Agency. (2019, May 1). UNDP Kazakhstan launches a Telegram GenderBot. https://www.lenta.inform.kz/ru/undp-kazakhstan-launches-a -telegram-genderbot_a3522426

Kim, J. Y., Fitzsimons, G. M., \& Kay, A. C. (2018). Lean in messages increase attributions of women's responsibility for gender inequity. Foumal of Personality and Social Psychology, 115(6), 974-1001. https://doi.org/10.1037/pspa0000129

King Abdullah University of Science and Technology. (2020). KAUST fellowship. https://a dmissions.kaust.edu.sa/phd-fellowship.html

Knobloch-Westerwick, S., Glynn, C. J., \& Huge, M. (2013). The Matilda effect in science communication: An experiment on gender bias in publication quality perceptions and collaboration interest. Science Communication, 35, 603-625. https://doi.org/10.1177/ 1075547012472684

Koch, J., Polnick, B., \& Irby, B. (Eds). (2014). Girls and women in STEM: A never ending story. Information Age Publishing.

Kuzhabekova, A., \& Almukhambetova, A. (2019). Women's progression through the leadership pipeline in the universities of Kazakhstan and Kyrgyzstan. Compare: $A$ Journal of Comparative and International Education, 1-19.

Law of the Republic of Kazakhstan on state guarantees of equal rights and equal opportunities for men and women $\S 223-I V$ ZRK. (2009). https://online.zakon.kz/Document/?doc_id= 30526983\#pos=2;-113

Litzler, E., Lange, S. E., \& Brainard, S. G. (2005). Climate for graduate students in science and engineering departments [Conference presentation]. Proceedings of the 2005 American Society for Engineering Education Annual Conference \& Exposition, Portland, OR.

Mason, M. A., Stacy, A., Goulden, M., Hoffman, C., \& Frasch, K. (2005, February). University of California faculty family friendly edge: An initiative for tenure-track faculty at the University of Califormia [Report]. University of California Berkeley. https://ucfam ilyedge.berkeley.edu/sites/default/files/ucfamilyedge.pdf 
McClure, E. R., Guernsey, L., Clements, D. H., Bales, S. N., Nichols, J., Kendall-Taylor, N., \& Levine, M. H. (2017). STEM starts early: Grounding science, technology, engineering, and math education in early childhood [Report]. The Joan Ganz Cooney Center at Sesame Workshop. https://joanganzcooneycenter.org/wp-content/uploads/2017/01/jgcc_ stemstartsearly_final.pdf

McLaughlin, K. (2018). Kazakhstan country gender assessment. Asian Development Bank.

Ministry of Justice of the Republic of Kazakhstan. (2016). Concept of family and gender policy in the Republic of Kazakhstan until 2030. https://www.akorda.kz/ru/npa-naciona lnoi-komissii

Moss-Racusin, C. A., Dovidio, J. F., Brescoll, V. L., Graham, M. J., \& Handelsman, J. (2012). Science faculty's subtle gender biases favor male students. Proceedings of the National Academy of Sciences of the United States of America, 109(41), 1-6.

National Testing Center. (2020). Unified national testing. www.testcenter.kz

Nazarbayev University. (2020). Nazarbayev University at a glance. https://nu.edu.kz/a bout-nazarbayev-university/nu-at-a-glance

Nazarbayev University School of Engineering and Digital Sciences. (2020). Faculty and research. https://seds.nu.edu.kz/faculty-and-research/faculty-list-2/

On approval of the State Program for the Development of Education and Science of the Republic of Kazakhstan for 2016-2019 § 460 (2018). https://zakon.uchet.kz/ rus/docs/P1800000460

Posselt, J. R. (2016). Inside graduate admissions: Merit, diversity, and faculty gatekeeping. Harvard University Press.

Primé, D. R., Bernstein, B. L., Wilkins, K. G., \& Bekki, J. M. (2015). Measuring the advising alliance for female graduate students in science and engineering: An emerging structure. Fournal of Career Assessment, 23(1), 64-78.

Sandberg, S., \& Scovell, N. (2013). Lean in - women, work and the will to lead. Knopf.

Seidakhmetova, B. (2019, August 8). STEM - идеи для Казахстана [STEM-ideas for Kazakhstan]. Komsomolskaya Pravda. https://www.kp.kz/daily/27010.1/4075826/

Taube, S., \& Polnick, B. (2014). Looking through a mirror with a third eye: Improving mathematics teaching in culturally diverse classrooms. In J. Koch, B. Polnick, \& B. Irby (Eds). Girls and women in STEM: A never ending story (pp. 193-216). Information Age Publishing.

UNESCO. (2016). Closing the gender gap in STEM: Drawing more girls and women into science, technology, engineering and mathematics. [UNESCO Asia-Pacific Education Thematic Brief]. UNESCO.

UNESCO. (2017). Cracking the code: Girls' and women's education in science, technology, engineering and mathematics (STEM). UNESCO.

UNICEF. (2020). UNICEF Launches Unisat nanosatellites program for girls [Press release]. https://www.unicef.org/kazakhstan/en/press-releases/unicef-launches-unisatnanosatellites-program-girls

U. S. Embassy and Consulate in Kazakhstan. (2020). 2020 TechGirls program. https:// kz.usembassy.gov/education-culture/opportunities/2019-techgirls/

U. S. Mission to International Organizations in Vienna. (2018, July 19). United States sends girls from Kazakhstan and Afghanistan to Colorado STEM summer camp. https:// vienna.usmission.gov/united-states-sends-girls-from-kazakhstan-and-afghanistan-to-color ado-stem-summer-camp/

Van Anders, S. M. (2004). Why the academic pipeline leaks: Fewer men than women perceive barriers to becoming professors. Sex Roles, 51(9-10), 511-521. 
Van Miegroet, H., Glass, C., Callister, R. R., \& Sullivan, K. (2019). Unclogging the pipeline: Advancement to full professor in academic STEM. Equality, Diversity and Inclusion: An International fournal, 39(2), 246-264.

Wang, M.-T., \& Degol, J. (2017). Gender gap in science, technology, engineering, and mathematics (STEM): Current knowledge, implications for practice, policy, and future directions. Educational Psychology Review, 29(1), 119-140. https:doi.org/ 10. 1007/s10648-10015-9355-

Weber, K. (2011). Role models and informal STEM-related activities positively impact female interest in STEM. Technology and Engineering Teacher, $71(3), 18$.

Wei-Cheng, M., Shr-Jya, C., Jiaqi, L, \& Johnson, E. (2020). Gender difference in STEM career aspiration and social-cognitive factors in collectivist and individualist cultures. Administrative Issues Foumal: Education, Practice E Research, 10(1), 30-46. https://doi.org/ 10.5929/2020.10.1.3

Willey, N. L. (2020). Parenting policies and culture in academia and beyond: Making it while mothering (and fathering) in the academy, and what COVID-19 has to do with it. Fournal of the Motherhood Initiative for Research and Community Involvement, 11(1), 201-217

$\mathrm{Xu}, \mathrm{Y} . \mathrm{J}$. (2008). Gender disparity in STEM disciplines: A study of faculty attrition and turnover intentions. Research in Higher Education, 49(7), 607-624.

Yoshikawa, K., Kokubo, A., \& Wu, C. H. (2018). A cultural perspective on gender inequity in STEM: The Japanese context. Industrial \& Organizational Psychology, 11, 301-309. https://doi.org/10.1017/iop.2018.19

Ysseldyk, R., Greenaway, K. H., Hassinger, E., Zutrauen, S., Lintz, J., Bhatia, M., Frye, M., Starkenburg, E., \& Tai, V. (2019). A leak in the academic pipeline: Identity and health among postdoctoral women. Frontiers in Psychology, 10, 1297. 